Annals of International Medical and Dental Research

E-ISSN: 2395-2822 | P-ISSN: 2395-2814

Vol-8, Issue-1 | January-February 2022

DOI: $10.53339 /$ aimdr.2022.8.1.16

Page no- 117-123 | Section- Research Article (Gastroenterology)

\title{
Prospective Evaluation of Raised Liver Transaminases in Asymptomatic Patients Attending OPD in a Tertiary Care Hospital
}

\author{
Vivek Ahuja1, Raghav Singhal2, Paraag Kumar ${ }^{3 *}$
}

\begin{abstract}
${ }^{1}$ Associate Professor, Department of Gastroenterology, MMIMSR, Mullana, Ambala, Haryana, India.

Email: vahuja2612@gmail.com Orcid ID: 0000-0001-8168-3795

2Resident, Department Gastroenterology, MMIMSR, Ambala, Haryana, India.

Email: raghavsag08@gmail.com

Orcid ID: 0000-0002-7566-9070

${ }^{3}$ Assistant Professor, Department of Gastroenterology, MMIMSR, Mullana, Ambala, Haryana, India.

Email: paraag2789@gmail.com

Orcid ID: 0000-0002-9192-3577
\end{abstract}

*Corresponding author

Received: 30 September 2021 Revised: 03 November 2021

Accepted: 14 November 2021

Published: 22 December 2021

\begin{abstract}
Background: Liver diseases are a cause of worldwide morbidity .The course is usually long and has no signs before the development of late stage disease. The only indicative markers are liver enzymes, such as aspartate aminotransferase (AST), alanine aminotransferase (ALT), and gamma glutamyl transferase (GGT) during asymptomatic period. There is a paucity of data from our subcontinent regarding the prevalence, risk factors and etiology of asymptomatic chronically raised liver enzymes. The aim of the study was to determine the prevalence, risk factors and etiology associated with unexplained chronically raised liver transaminases in patients attending OPD in a tertiary care hospital. Methods: This was a prospective study conducted in the Department of Gastroenterology, MMIMSR, Mullana from July 2019-Dec 2020 in 50 patients who presented with chronically raised liver enzymes. Detailed comprehensive history, physical examination and investigation was done to identify etiology and risk factors associated with raised liver enzymes. Results: 566 patients were screenedfor inclusion in the study. The prevalence of raised transaminases in asymptomatic patients was $9.4 \%$. NAFLD was the most common etiology of raised liver transaminases, seen in $70 \%$ of patients followed by Hepatitis C and Hepatitis B. Dyslipidemia was the most important risk factor associated with NAFLD. Conclusion: NAFLD should be kept in mind while dealing patients with unexplained transaminitis. Earlier detection could help halt the progression to chronic liver disease.
\end{abstract}

Keywords:- ALT, AST, NAFLD.

\section{INTRODUCTION}

Liver disease is a major public health problem worldwide, leading to serious illness and death. Patients with liver disease need longterm medical advice,frequent hospital visits and admissions. The most common causes of liver disease include alcoholism, hepatitis B virus (HBV), hepatitis $\mathrm{C}$ virus (HCV) and fatty liver disease (NAFLD). The etiology of liver disease varies, depending on the location and population. Changes in life style and the epidemic of obesity, diabetes, high blood pressure, dyslipidemia and eventually metabolic syndrome have led to an increase in the prevalence of NAFLD worldwide.[1]

The course of liver disease is long and usually undetectable before the development of late stage disease. During this asymptomatic period, the only symptoms that can indicate 
Annals of International Medical and Dental Research

E-ISSN: 2395-2822 | P-ISSN: 2395-2814

Vol-8, Issue-1 | January-February 2022

DOI: 10.53339 /aimdr.2022.8.1.16

Page no- 117-123 | Section- Research Article (Gastroenterology)

liver damage are liver enzymes, such as alanine aminotransferase (ALT), aspartate aminotransferase (AST) and gamma glutamyl transferase (GGT). Among aminotransferases, ALT is a critical indicator of liver cell damage and has been used for nearly 60 years to diagnose liver disease. [2]

Studies based on population from the US, Italy, Taiwan and China have shown that the most common cause of high ALT and liver damage is thought to be NAFLD in these countries. $[3,4,5,6]$ There is a paucity of data regarding the etiology of elevated transaminases in our country. Hence, this study was conducted on patients presenting in Gastoenterology out patient department in a tertiary care hospital to determine prevalence, risk factors and etiology associated with unexplained chronically raised liver transaminases.

\section{MATERIAL AND METHODS}

This was a prospective study conducted in the Department of Gastroenterology, Maharishi Markandeshwar Institute of Medical Sciences \& Research (MMIMSR), Mullana. Patients presenting in the OPD were prospectively enrolled from July 2019 onwards till 50 patients were included in the study

\section{Inclusion Criteria}

- Patients having ALT or AST above normal range (at least two times above normal limits)for more than 3 months.

- Age $>18$ years

- Patients with normal alkaline phosphatase.

Exclusion Criteria

- Those who have history of chronic viral hepatitis or non viral liver disease.

- Pregnant females
- Chronically ill patients

- Patients having a discrete mass in the liver by an imaging procedure.

- Those having history of intravenous drug abuse, HIV infection or history of malignancy.

- Those who refused to give consent.

After screening with the above mentioned criteria, 50 patients were included in the study. All the particulars of the patients were obtained as per a preset proforma. A detailed clinical history was taken and a thorough clinical examination was done. Following this, relevant blood investigations were done as required. These included complete blood count ,prothrombin time/INR, C-reactive protein (CRP) levels, fasting blood sugar, Glycated Hemoglobin (HbA1C), TSH, HbsAg (by elisa), Anti HCV (by elisa) and lipid profile. Ultrasound abdomen was also done as required. If above test were inconclusive in making diagnosis then further laboratory investigation like serum ceruloplasmin, Antinuclear antibodies (ANA), Antimitochondrial antibody (AMA), Smooth muscle antibody (SMA), ANTI LKM-1(liver Kidney Microsomal), Serum Immunoglobulin levels, IgA ttG (tissue transglutaminase) and Serum ferritin were also done.

Diagnosis of NAFLD was made on clinical and radiological parameters after excluding other causes of liver disease. History of significant alcohol intake was excluded before diagnosing a patient with NAFLD.

All statistical analysis were performed using SPSS software (version 18.0, SPSS Inc., Chicago, IL). Continuous data were expressed as mean \pm standard deviation and analyzed 
Annals of International Medical and Dental Research

E-ISSN: 2395-2822 | P-ISSN: 2395-2814

Vol-8, Issue-1 | January-February 2022

DOI: $10.53339 /$ aimdr.2022.8.1.16

Page no- 117-123 | Section- Research Article (Gastroenterology)

using independent sample $t$-tests, whereas categorical variables were expressed as quantities and analyzed using the MannWhitney test. Correlations between the variables were estimated using Spearman's rank order correlation coefficient $(r) . p$ values of $<0.05$ were considered significant for the analysis.

\section{RESULTS}

566 patients presenting to OPD of Gastroenterology department were screened for inclusion into the study. Of them 53 cases fulfilled the inclusion criteria. 3 patients did not give consent and thus were excluded from the study. Thus, the prevalence of raised transaminases in asymptomatic patients was $9.4 \%$. The analysis was done on the 50 patients included in the study.

Mean age of patients with raised transaminase level was $37.6 \pm 8.9$ years (range-18 to 55 years). Majority of cases belonged to 40 to 49 years of age $(38 \%)$.

$74 \%$ cases were males and $26 \%$ cases were females. Thus, male preponderance was observed with male : female ratio of $2.8: 1$.
NAFLD was the most common etiology found in our study accounting to $70 \%$ of total cases. It was followed by hepatitis C (10\%) and hepatitis B $(8 \%)$.

NAFLD was observed in majority of patients belonging to age range of 30 to 39 years $(42.9 \%)$, followed by $37.1 \%$ cases belonging to 40 to 49 years. Also, NAFLD was observed in $71.4 \%$ males. However, we observed no significant association of NAFLD with age and gender $(p>0.05)$. Though, NAFLD was observed in higher proportions of cases with higher BMI and raised waist circumference, the association was statistically insignificant $(p>0.05)$. NAFLD was observed in significantly higher proportions of males with raised cholesterol and triglyceride level $(p<0.05)$.

History of drugs and surgery were the most common risk factors observed in $28 \%$ cases each and history of blood transfusion was least common risk factor observed in $6 \%$ cases with raised transaminase levels.

Table 1: Gender wise distribution of patients according to age.

\begin{tabular}{|l|l|l|l|l|}
\hline \multirow{2}{*}{ Age } & Male(n=37) & Female(n=13) \\
\cline { 2 - 5 } & $\mathbf{n}$ & $\mathbf{0}$ & $\mathbf{n}$ & $\mathbf{0}$ \\
\hline $18-29$ & 7 & 18.9 & 3 & 23.1 \\
\hline $30-39$ & 12 & 32.4 & 5 & 38.5 \\
\hline $40-49$ & 15 & 40.5 & 4 & 30.8 \\
\hline$>50$ & 3 & 8.1 & 1 & 7.7 \\
\hline
\end{tabular}

Table 2: Distribution of patients according to Etiology of liver disease

Etiology

Celiac Disease
Number of patients $(n=50)$

1
Percentage

2.0 
Annals of International Medical and Dental Research

E-ISSN: 2395-2822 | P-ISSN: 2395-2814

Vol-8, Issue-1 | January-February 2022

DOI: 10.53339/aimdr.2022.8.1.16

Page no- 117-123 | Section- Research Article (Gastroenterology)

\begin{tabular}{|l|l|l|}
\hline Hepatitis B & 4 & 8.0 \\
\hline Hepatitis C & 5 & 10 \\
\hline Hep B + Hep C & 1 & 2.0 \\
\hline NAFLD & 35 & 70 \\
\hline Undiagnosed & 4 & 8.0 \\
\hline
\end{tabular}

Table 3: Association of NAFLD with various variables

\begin{tabular}{|c|c|c|c|c|}
\hline \multirow{2}{*}{\multicolumn{2}{|c|}{ Variables }} & \multicolumn{2}{|l|}{ NAFLD } & \multirow[t]{2}{*}{ P value } \\
\hline & & Absent (\%) & Present (\%) & \\
\hline \multirow[t]{4}{*}{ Age (years) } & $18-29$ & $4(26.7)$ & $6(17.1)$ & \multirow[t]{4}{*}{0.07} \\
\hline & $30-39$ & $2(13.3)$ & $15(42.9)$ & \\
\hline & $40-49$ & $6(40)$ & $13(37.1)$ & \\
\hline & $>50$ & $3(20)$ & $1(2.9)$ & \\
\hline \multirow[t]{2}{*}{ Gender } & Male & $12(80)$ & $25(71.4)$ & 0.53 \\
\hline & Female & $3(20)$ & $10(28.6)$ & \\
\hline \multicolumn{2}{|l|}{$\mathrm{BMI}>23 \mathrm{~kg} / \mathrm{m} 2$} & $11(73.3)$ & $28(80)$ & 0.49 \\
\hline \multicolumn{2}{|c|}{ Waist circumference(raised) } & $9(60)$ & $25(71.4)$ & 0.43 \\
\hline \multirow[t]{2}{*}{ Cholesterol>200 } & Male & $2(16.7)$ & $17(68)$ & 0.003 \\
\hline & Female & $0(0)$ & $5(50)$ & 0.12 \\
\hline \multirow[t]{2}{*}{ Triglycerides $>150$} & Male & $3(25)$ & $18(72)$ & 0.007 \\
\hline & Female & $1(33.3)$ & $8(80)$ & 0.13 \\
\hline \multirow[t]{2}{*}{ LDL>100 } & Male & $9(75)$ & $22(88)$ & 0.32 \\
\hline & Female & $2(66.7)$ & $5(50)$ & 0.61 \\
\hline \multirow[t]{2}{*}{ HDL } & Male & $5(41.7)$ & $11(44)$ & 0.89 \\
\hline & Female & $2(66.7)$ & $1(10)$ & 0.04 \\
\hline
\end{tabular}

Table 4: Distribution according to risk factors

\begin{tabular}{|l|l|l|}
\hline Risk factors & Number of patients $(\mathbf{n}=50)$ & Percentage \\
\hline Drugs & 14 & 28.0 \\
\hline Surgery in past & 14 & 28.0 \\
\hline Blood transfusion history & 3 & 6.0 \\
\hline Intravenous drug use & 0 & 0 \\
\hline Unsafe sex & 9 & 18.0 \\
\hline Tattooing & 6 & 12.0 \\
\hline
\end{tabular}

\section{DISCUSSION}

Raised ALT levels is an indicative marker of hepatocellular damage in acute and chronic hepatitis. Epidemiological data on the prevalence, etiology and risk factors for transaminitis comes from the studies on blood donors and patients seeking medical care 
Annals of International Medical and Dental Research

E-ISSN: 2395-2822 | P-ISSN: 2395-2814

Vol-8, Issue-1 | January-February 2022

DOI: $10.53339 /$ aimdr.2022.8.1.16

Page no- 117-123 | Section- Research Article (Gastroenterology)

which results in a selection and referral bias. We assessed the prevalence, etiology and risk factors for unexplained chronically raised liver transaminases in patients attending OPD in a tertiary care hospital. A total of 566 participants were included in the study of which 53 fulfilled the inclusion criteria, Out of 53 participants, 3 did not give consent and hence were excluded.

Prevalence of unexplained chronically raised liver transaminases was $9.4 \%(53 / 566)$ in our study. Previous community based studies from Europe (Italy) showed a prevalence of $7.6 \%$ in Sicily, $10 \%$ in Campania region (single measurement of ALT was done). ${ }^{[7,8]}$ Both these towns of south Italy have a high prevalence of $\mathrm{HCV}$ infection and $37-47 \%$ of the participants with elevated ALT had HCV RNA positive. The Third National Health and Nutrition Examination Survey (NHANES III) between 1988 to 1994 conducted in United States found that prevalence of raised aminotransferase in adult population was $7.9 \%$ (single measurement). [3] There have been no population based studies in India. Elevated ALT levels have been noted in $11.9-16.5 \%$ of blood donors (considered to represent normal population) in various studies. $[9,10]$

In our study, elevated transaminases were more common in males $(74 \%)$ than in females $(26 \%)$ and most of the participants were between 30 and 49 years of age (72\%).

NAFLD was the most common etiology of raised liver transaminases seen in $70 \%$ of our study population. High BMI and visceral obesity are well established risk factors for NAFLD. In our study, four fifths of the participants were either obese $(62 \%)$ or overweight $(16 \%)$. Of these, more than half had NAFLD. Age and gender are also associated with a differential prevalence of NAFLD. In various studies all over world, NAFLD seems to be more common in males with its prevalence increasing with increase in age. $[11,12,13]$ In our study, $71.4 \%$ of the participants with NAFLD were males, but the prevalence of NAFLD was seen to be maximum in the third decade due to higher BMI. This highlights about the increasing trend of obesity related illness in the younger age groups. In various other studies from our subcontinent, NAFLD was more commonly seen in males which is also the case in our study. However, the prevalence of obesity and dyslipidemia was more in our study as compared to other studies. Out of the various risk factors for NAFLD in our study, high cholesterol and LDL in males and low HDL levels in females seem to significantly increase $(p<0.05)$ the risk of NAFLD. However, other risk factors like BMI, waist circumference and triglyceride levels, which are otherwise known to be associated with metabolic syndrome and NAFLD, were not significantly related to NAFLD in our study group.

The next most common etiologies were Hepatitis C $(10 \%$ and Hepatitis B $(8 \%)$. In other Indian studies, Anti-HCV positivity was found to be $3-13 \%$ in individuals with elevated ALT which was similar to our study group. Population based studies have shown anti $\mathrm{HCV}$ positivity rate between $0.1-0.87 \%$ in India. $[14,15]$ In our hospital, a large number of patients are attending OPD from the nearby Saharanpur area and other adjoining districts of Uttar Pradesh. These areas have relatively higher prevalence of Hepatitis $\mathrm{C}$ in the the 


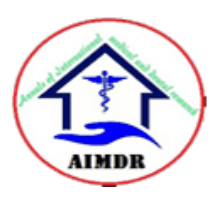

Annals of International Medical and Dental Research

E-ISSN: 2395-2822 | P-ISSN: 2395-2814

Vol-8, Issue-1 | January-February 2022

DOI: $10.53339 /$ aimdr.2022.8.1.16

Page no- 117-123 | Section- Research Article (Gastroenterology)

community. This could also be the reason for slightly higher Anti-HCV positivity in our study group.

India has the second largest pool of chronic HBV carriers in the world.116] In our study also, $\mathrm{HbsAg}$ positivity was seen in $8 \%$. Other less common causes for transaminitis were Celiac disease in 2\% and Hepatitis B and C coinfection in $2 \% .4$ patients remained undiagnosed despite of extensive work up.

Among the patients with positive HbsAg, the possible risk factors were unprotected sexual intercourse $(44 \%)$ and past history of surgery (28\%).Only one of the positive HbsAg patient had received blood products in past and had a history of tattooing. No significant association of $\mathrm{HCV}$ with risk factors was seen in our study.

\section{REFERENCES}

1. Chitturi S, Farrell GC, George J. Non-alcoholic steatohepatitis in the Asia-Pacific region: future shock? J Gastroenterol Hepatol. 2004;19(4):368-74. doi: 10.1111/j.1440-1746.2003.03252.x.

2. Karmen A, Wroblewski F, Ladue JS. Transaminase activity in human blood. J Clin Invest. 1955;34(1):126-31. doi: 10.1172/JCI103055.

3. Clark JM, Brancati FL, Diehl AM. The prevalence and etiology of elevated aminotransferase levels in the United States. Am J Gastroenterol. 2003;98(5):960-7. doi: 10.1111/j.15720241.2003.07486.x.

4. Pendino GM, Mariano A, Surace P, Caserta CA, Fiorillo MT, Amante A, et al; ACE Collaborating Group. Prevalence and etiology of altered liver tests: a population-based survey in a Mediterranean town. Hepatology. 2005;41(5):1151-9. doi: 10.1002/hep.20689.

5. Chen $\mathrm{CH}$, Huang $\mathrm{MH}$, Yang JC, Nien CK, Yang CC, Yeh YH, et al. Prevalence and etiology of elevated serum alanine aminotransferase level in an adult population in Taiwan. J Gastroenterol Hepatol.

\section{CONCLUSIONS}

The estimated prevalence of chronically raised liver transaminases is $9.4 \%(53 / 566)$ in our study group. Raised transaminases were more common in males than females with most of the participants between 30 to 49 years of age $(72 \%)$. The most common etiologies of chronically raised liver transaminases were NAFLD and chronic HCV infection. Dyslipidemia in males was commonest risk factor associated with NAFLD. Incidence of NAFLD is growing at a rapid pace in our country. A strong suspicion should be kept while dealig with patients with asymptomatic transaminitis. Early detection of the disease will help in halting the progression to advanced liver disease.

2007;22(9):1482-9.

doi:

$10.1111 /$ j.1440-

1746.2006.04615.x

6. Zhang H, He SM, Sun J, et al. Prevalence and etiology of abnormal liver tests in an adult population in Jilin, China. Int J Med Sci. 2011;8(3):254-262. Published doi:10.7150/ijms.8.254

7. Iwatsuki $\mathrm{K}$, Akihisa $\mathrm{T}$, Tokuda $\mathrm{H}$, Ukiya $\mathrm{M}$, Higashihara H, Mukainaka T, et al. Sterol ferulates, sterols, and 5-alk(en)ylresorcinols from wheat, rye, and corn bran oils and their inhibitory effects on Epstein-Barr virus activation. J Agric Food Chem. 2003;51(23):6683-8. doi: 10.1021/jf030371+.

8. Maio G, d'Argenio P, Stroffolini T, Bozza A, Sacco $\mathrm{L}$, Tosti ME, et al. Hepatitis $\mathrm{C}$ virus infection and alanine transaminase levels in the general population: a survey in a southern Italian town. J Hepatol. 2000;33(1):116-20. doi: 10.1016/s01688278(00)80167-1.

9. Nagaraju K, Misra S, Saraswat S, Choudhary N, Masih B, Ramesh V, et al. High prevalence of HBV infectivity in blood donors detected by the dot blot hybridisation assay. Vox Sang. 1994;67(2):183-6. doi: 10.1111/j.1423-0410.1994.tb01656.x. 
Annals of International Medical and Dental Research

E-ISSN: 2395-2822 | P-ISSN: 2395-2814

Vol-8, Issue-1 | January-February 2022

DOI: 10.53339/aimdr.2022.8.1.16

Page no- 117-123 | Section- Research Article (Gastroenterology)

10. Choudhury N, Ramesh V, Saraswat S, Naik S. Effectiveness of mandatory transmissible diseases screening in Indian blood donors. Indian J Med Res. 1995;101:229-32.

11. Amarapurkar D, Kamani P, Patel N, Gupte P, Kumar P, Agal S, et al. Prevalence of non-alcoholic fatty liver disease: population based study. Ann Hepatol. 2007;6(3):161-3.

12. Vernon G, Baranova A, Younossi ZM. Systematic review: the epidemiology and natural history of non-alcoholic fatty liver disease and non-alcoholic steatohepatitis in adults. Aliment Pharmacol Ther. 2011;34(3):274-85. doi: $\quad 10.1111 /$ j.13652036.2011.04724.x.

13. Li H, Wang YJ, Tan K, Zeng L, Liu L, Liu FJ, et al. Prevalence and risk factors of fatty liver disease in Chengdu, Southwest China. Hepatobiliary Pancreat Dis Int. 2009;8(4):377-82.
14. Chadha MS, Tungatkar SP, Arankalle VA. Insignificant prevalence of antibodies to hepatitis $C$ in a rural area of western Maharashtra. Indian J Gastroenterol. 1999; 18(1):22-3.

15. Chowdhury A, Santra A, Chaudhuri S, Dhali GK, Chaudhuri S, Maity SG, et al. Hepatitis C virus infection in the general population: a communitybased study in West Bengal, India. Hepatology. 2003;37(4):802-9. doi: 10.1053/jhep.2003.50157.

16. Datta $S$. An overview of molecular epidemiology of hepatitis B virus (HBV) in India. Virol J. 2008;5:156. doi: 10.1186/1743-422X-5-156.

Source of Support: Nil, Conflict of Interest: None declared 